\title{
Kjøring under påvirkning av amfetamin og metamfetamin
}

\author{
Sammendrag \\ Bakgrunn. De sentralnervøst stimule- \\ rende midlene amfetamin og metamfe- \\ tamin påvises ofte i blodprøver fra bil- \\ førere mistenkt for kjøring i påvirket \\ tilstand.
}

\begin{abstract}
Materiale og metode. Artikkelen er basert på søk i databasene PubMed og Google Scholar. Det vi har av kunnskap om amfetaminpreparaters effekter på trafikkferdigheter blir referert og diskutert.
\end{abstract}

Resultater. Det finnes noen epidemiologiske studier, men svært få eksperimentelle undersøkelser, på dette feltet. I studier av selekterte, søvndepriverte forsøkspersoner er lave doser amfetaminer assosiert med økt yteevne, mens eksperimentelle studier med høye amfetamindoser mangler. Teoretiske betraktninger og empiri tilsier at høyere doser kan gi prestasjonsforringelse, men uten klassiske konsentrasjoneffekt-relasjoner.

Fortolkning. Kunnskapsgrunnlaget for håndtering av bl.a. veitrafikksaker der bilførere har brukt amfetaminpreparater, er mangelfullt.

\section{Kjersti Lia}

Institutt for laboratoriemedisin,

barne- og kvinnesykdommer

Norges teknisk-naturvitenskapelige universitet

\section{Olav Spigset}

Avdeling for klinisk farmakologi

St. Olavs hospital

og

Institutt for laboratoriemedisin,

barne- og kvinnesykdommer

Norges teknisk-naturvitenskapelige universitet

\section{Lars Slørdal}

lars.slordal@ntnu.no

Institutt for laboratoriemedisin

barne- og kvinnesykdommer

Norges teknisk-naturvitenskapelige universitet 7489 Trondheim

og

Avdeling for klinisk farmakologi

St. Olavs hospital

I Norge påvises hvert år andre rusmidler enn alkohol hos noe over 4000 bilførere som stoppes eller pågripes av politiet etter påfallende kjøring (1). De misbruksstoffene som oftest påvises, er benzodiazepiner, cannabis og amfetamin/metamfetamin, hvorav sistnevnte gruppe står for omtrent $1 / 3$. I epidemiologiske studier er det funnet en 2-3 ganger øt risiko for å bli involvert i trafikkulykker etter bruk av amfetamin/metamfetamin (2-4). Til sammenlikning er risikoøkningen ved bruk av benzodiazepiner beregnet til å være dobbelt så stor som hos amfetaminpåvirkede (4). Resultatene fra denne typen studier er imidlertid beheftet med betydelig metodologisk usikkerhet.

Av vanlig brukte misbruksstoffer har amfetamin og metamfetamin en særstilling ved at de har en stimulerende effekt på sentralnervesystemet. Det finnes også holdepunkter for at midlene i noen grad kan ha prestasjonsfremmende effekter (5). Piloter i det amerikanske forsvaret har mulighet til å bruke amfetamin under langvarige oppdrag for å hindre tretthet og bedre konsentrasjon og ferdigheter. Under innledningen av Irakkrigen brukte pilotene på bombeflyet B-2 amfetamin på $2 / 3$ av alle oppdrag, og $97 \%$ av pilotene rapporterte at bruken hadde en gunstig effekt (6).

Inntak av en rusgivende dose amfetamin eller metamfetamin kan føre til en rekke psykiske og fysiske effekter. I rusgivende doser er vanlige effekter en følelse av økt energi, økt oppmerksomhet, forsterket selvbilde, økt pratsomhet og rastløshet, manglende sultfølelse, nedsatt søvnbehov, samt økt puls og blodtrykk (7).
På bakgrunn av at amfetamin og/eller metamfetamin ofte påvises hos bilister som etterforskes for påfallende kjøring, samtidig som amfetamin brukes som prestasjonsfremmende middel i andre sammenhenger, ønsket vi å undersøke hva som er kjent om disse stoffenes effekt på kjøreferdigheter i kontrollerte studier. Medisinsk bruk av amfetaminpreparater ved tilstander som for eksempel hyperkinetiske forstyrrelser, omtales ikke.

\section{Materiale og metode}

Denne artikkelen er basert på en ikke-systematisk litteraturgjennomgang ved hjelp av søk i PubMed og Google Scholar. Vi har inkludert studier gjort på mennesker og $\mathrm{i}$ all hovedsak fokusert på kontrollerte, dobbeltblinde studier.

\section{Farmakologi}

Amfetamin og metamfetamin virker ved å øke utskillingen av biogene aminer fra nevroner i sentralnervesystemet (7). Økt oppmerksomhet, anoreksi og rastløshet tilskrives stimulering av noradrenalinutskillingen. Økt frisetting av dopamin og serotonin, som i økende grad forekommer ved høye doser, fremholdes som ansvarlig for de tanke- og persepsjonsforstyrrelsene som kan forekomme. I løpet av få dagers kontinuerlig bruk tømmes de presynaptiske lagrene gradvis for disse nevrotransmitterne. Dette fører til at frigjøringen av transmittere til synapsene reduseres og rusopplevelsen avtar - eller fordrer gjentatte og stadig høyere doser for å bevare effekten. Denne selvbegrensende effekten er en grunn til at disse midlene vanligvis brukes i begrensede tidsperioder (amphetamine runs) atskilt av perioder på inntil flere uker uten amfetaminbruk. Den spesielle og

\section{Hovedbudskap}

- Det er mangelfull kunnskap om hvordan amfetaminer påvirker trafikkatferd

- Eksperimentelle studier tyder på at lave doser amfetaminer har indifferent eller prestasjonsfremmende effekt på trafikkatferd

- Epidemiologiske studier tyder på at høye doser amfetaminer gir trafikkfarlig prestasjonsforringelse

- Amfetaminer følger sannsynligvis ikke klassiske dose-effekt-sammenhenger 
tidsavhengige rusopplevelsen som amfetamin og metamfetamin gir, er ofte blitt illustrert med hysteresekurver (fig 1) (8).

Det har vært gjort forsøk på å korrelere graden av påvirkning til blodkonsentrasjonene av amfetamin og metamfetamin. I en norsk undersøkelse ble det presentert data fra 878 bilførere som var blitt pågrepet for kjøring i påvirket tilstand og fått påvist amfetamin eller metamfetamin, men ingen andre misbruksstoffer, i blodet (9). Det ble funnet en statistisk signifikant - men ikke spesielt markant - sammenheng mellom blodkonsentrasjonen av stoffene og påvirkningsgrad slik dette ble vurdert etter en standardisert klinisk undersøkelse. I alt ble $27 \%$ av førerne vurdert som ikke påvirket ved klinisk undersøkelse, mens $73 \%$ ble vurdert som påvirket. Det var ingen signifikante forskjeller i blodnivåene av amfetaminer mellom de som klinisk ble vurdert som påvirket og de som ble vurdert som ikke påvirket (9). I en senere svensk studie hvor atskillig færre bilførere $(\mathrm{n}=70)$ inngikk i analysen, ble det ikke påvist noen korrelasjon mellom amfetaminnivå i blodprøve og eventuell påvirkningsgrad ved klinisk undersøkelse (10).

\section{Kontrollerte studier}

Det finnes et fåtall kontrollerte studier som har undersøkt i hvilken grad amfetamin, vanligvis gitt som den aktive enantiomeren dekstroamfetamin (d-amfetamin), påvirker egenskaper som anses viktige for trygg ferdsel i veitrafikken. Eksempler på slike egenskaper er grad av sjansetaking, reaksjonstid, oppmerksomhet og kognitiv og psykomotorisk funksjon. I noen av studiene er det anvendt enkle tester der forsøkspersonene for eksempel kun har utført én isolert arbeidsoppgave, mens andre studier har brukt komplekse testbatterier, inklusive kjøresimulator. Aktuelle dobbeltblinde studier der amfetamin i en eller flere ulike doser er sammenliknet mot placebo og/eller innbyrdes, er oppsummert i tabell 1 (11-20).

I 1962 ble det publisert en kontrollert studie der grad av risikotaking i en spillsituasjon med sigaretter ble undersøkt (11). Det viste seg at forsøkspersonene tok større sjanser når de hadde fått amfetamin, noe som ble tatt til inntekt for hypotesen om at amfetamin øker risikoatferd.

I perioden 1973-90 ble det utført flere studier av atferd relatert til oppmerksomhet etter inntak av amfetamin (12-16). Kvinner og menn i 30-årene, både rusnaive og rusbrukere, ble gitt amfetamin i engangsdoser på 1-35 mg. Deltakerne gjennomgikk deretter hørselstester, visuelle tester, psykologiske selvmonitoreringstester, motoriske tester m.m. (tab 1). Alle studiene viste bedret effekt ved bruk av amfetamin både på nøyaktighet og hastighet ved utføring av de ulike oppgavene.

Etter dette er det publisert fire studier som har sett på egenskaper som mer direkte er relatert til bilkjøring (17-20). I den første av disse ble åtte menn som tidligere hadde eksperimentert med illegale rusmidler, inkludert $\mathrm{i}$ en overkrysningsstudie der d-amfetamin i doser på $10 \mathrm{mg} \mathrm{og} 30 \mathrm{mg}$ ble sammenliknet med placebo (17). Amfetamin hadde ingen vesentlige effekter på utføring av ulike kognitive, motoriske og perseptive oppgaver, men det lave antallet forsøkspersoner kan maskere forskjeller som i andre sammenhenger kan være klinisk viktige.

I en annen studie sammenliknet man effekten av 25 mg d-amfetamin og placebo på psykomotoriske ferdigheter hos 25 friske frivillige forsøkspersoner (18). Amfetamingruppen hadde signifikant redusert reaksjonstid de første 3-6 timene etter inntak. Subjektivt følte de som fikk amfetamin at de hadde større mentalt overskudd (energetic) og var mer snartenkte, men også mer likeglade (lightheaded) og engstelige sammenliknet med placebogruppen. Maksimal plasmakonsentrasjon av amfetamin var i gjennomsnitt $300 \mathrm{nmol} / 1$ etter 3,5 timer. Den forkortede reaksjonstiden syntes ikke å ha sammenheng med plasmakonsentrasjonen av amfetamin.

I den eneste studien vi fant som er utført $i$ kjøresimulator, ble effekten av 0,42 mg d-amfetamin per kg kroppsvekt (dvs. $30 \mathrm{mg}$ til en person på $70 \mathrm{~kg}$ ) sammenliknet med placebo hos 20 personer som alle hadde brukt illegalt amfetamin tidligere, men sjeldnere enn én gang i måneden (19). Deltakerne hadde minimum tre års kjøreerfaring. Simulatoren anvendte scenarier med både dagkjøring, nattkjøring, bykjøring og landeveiskjøring. Den gjennomsnittlige blodkonsentrasjonen av amfetamin var $610 \mathrm{nmol} / 1$ rett før simulatortesting ble utført (120 minutter etter inntak av amfetamin) og $730 \mathrm{nmol} / 1$ rett etter at testen var avsluttet (170 minutter etter inntak).

Resultatene viste en forhøyet feilprosent $\mathrm{i}$ simulert kjøring på dagtid sammenliknet med placebo. De vanligste feilene gjaldt reaksjoner på og bruk av lyssignaler, og reaksjonstidene var også forlenget. Det ble derimot ikke målt noen forskjeller i nattkjøringsscenarier. Man konkluderte med at amfetamin gir en viss reduksjon av kjøreferdighet på dagtid og tolket resultatene som konsistente med det tunnelsynet som er assosiert med amfetamininntak (19). I studien var det ikke utfall ved en klinisk standardundersøkelse for rusmiddelpåvirkning som inkluderte nystagmus, gang- og balansetester (21). Disse elementene inngår også i den kliniske testen som brukes i Norge ved mistanke om kjøring under påvirkning av andre rusmidler enn alkohol.

Den samme forskergruppen publiserte noe senere en studie av effektene av den samme dosen d-amfetamin på kjørerelaterte kognitive funksjoner (20). Selv om amfetamin svekket utføringen av visuelle oppgaver, var resultatene bedre med amfetamin enn med placebo når det gjaldt utføring av oppgaver relatert til oppmerksomhet, psykomotorisk funksjon og persepsjonshastighet.

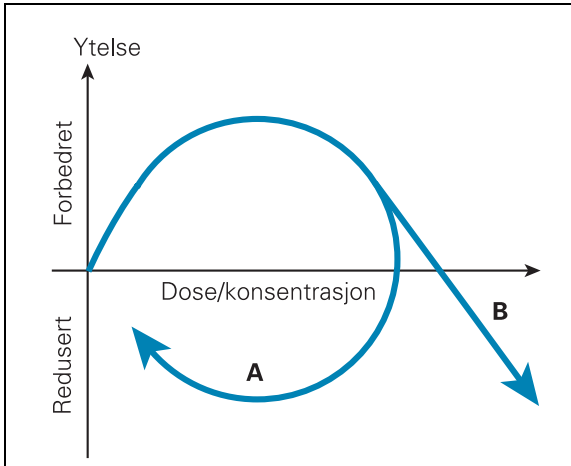

Figur 1 Hysteresekurve for dose-/konsentrasjonsavhengig ytelses-/prestasjonsnivå under påvirkning av amfetamin eller metamfetamin, først foreslått av Ellinwood \& Nikaido (8). Kurveforløpet tilbake til origo (A) kan illustrere begrenset bruk, mens en ytterligere prestasjonsforverring som funksjon av dose eller konsentrasjon (B) kjennetegner protrahert bruk over lengre tid

En rekke søvndeprivasjonsstudier (22-31) der man undersøker amfetamins effekter på yteevne, er i all hovedsak gjennomført i militær regi (22-30). Gjennomgående viser disse studiene at amfetamin har prestasjonsfremmende effekter hos personer med søvnunderskudd. I den mest oppsiktsvekkende av undersøkelsene ble militære piloter testet med helikopterflyging over en 64-timersperiode der de ved tre anledninger inntok d-amfetamin $(10 \mathrm{mg})$ eller placebo. De som fikk amfetamin, presterte best bak spakene og følte seg mindre slitne og i bedre vigør (30).

\section{Diskusjon}

Observasjonsstudier av bilførere og av piloter som har inntatt amfetamin, tar utgangspunkt i sterkt selekterte populasjoner. Det dreier seg enten om misbrukere som har lagt for dagen uhensiktsmessig trafikkatferd i en slik grad at de er blitt involvert i trafikkulykker, trafikkdrept eller stoppet og underkastet en nærmere undersøkelse (2-4), eller høyt utdannede og motiverte krigsflygere som deltar i eller trener for deltakelse i kamphandlinger $(5,6)$. Slike observasjonsstudier er lite egnet til å gi valid og overførbar informasjon om amfetamineffekter i trafikken.

De eksperimentelle studiene som er publisert (11-31), imøtekommer heller ikke vårt behov for informasjon. For det første er studiene gjennomgående utført med lave amfetamindoser som har resultert i maksimalkonsentrasjoner vesentlig lavere enn $1 \mu \mathrm{mol} / 1$. I den kontrollerte studien som anvendte den høyeste dosen $(0,9-1,0 \mathrm{mg} / \mathrm{kg}$ kroppsvekt, noe som ga maksimale plasmanivåer i området 320-970 nmol/1, med gjennomsnittsnivåer på $690 \mathrm{nmol} / \mathrm{l})$, ble forsøkspersonene ikke ferdighetstestet (32). Til sammenlikning vil individer som pågripes og/eller dømmes for kjøring under påvirkning av amfetamin eller metamfetamin i Norge oftest ha fått påvist blodkonsentrasjoner over $1 \mu \mathrm{mol} / 1(33,34)$. 
For det andre er resultatene fra de eksperimentelle studiene motstridende. Noen studier har konkludert med at amfetamin øker risikoatferd (11), ikke forbedrer motorisk funksjon $(14,15)$, eller reduserer kjøreferdigheter (19). Andre studier har funnet at amfetamin bedrer utføring av oppgaver relatert til læring og oppmerksomhet, psykomotorisk funksjon og perseptuell hastighet $(12-16,20)$. Til sist finnes det også én studie som fant at amfetamin ikke hadde noen effekt på utføring av forskjellige kognitive, motoriske og perseptive oppgaver (17). Ut fra de respektive studiene konkluderes det med at amfetamin ikke påvirker (17), kan fremme $(12-16,20)$ eller kan svekke $(11$, 19) kjøreferdighetene.

Søvndeprivasjonsstudiene oppviser på den annen side langt mer homogene resultater (22-31). Samtlige nyere studier (23-31) viser at amfetamin i doser på 20-30 mg bedrer oppmerksomhet og kognitiv og psykomotorisk prestasjonsevne ved søvnmangel, mens en eldre studie ikke har vist effekt av amfetamin på fysisk krevende oppgaver (22). Det amerikanske forsvaret har rutiner som innebærer at piloter kan bruke 5-10 mg dekstroamfetamin ved behov på langvarige stridsoppdrag, eventuelt i gjentatte doser. I gjennomsnitt er inntatt dose hos en jagerpilot på oppdrag som varer 15-35 timer, i størrelsesorden 15-20 mg (6).

Når effektene av amfetamin/metamfetamin er beskrevet med hysteresekurver (fig 1), er dette basert på inntak av rusgivende doser, det vil si doser som gjerne er over $100 \mathrm{mg}$, og som brukes gjentatte ganger over tidsperioder på et eller noen få døgn avbrutt av perioder på en uke eller mer uten eksposi- sjon. Det finnes ikke spesifikk dokumentasjon for at trafikkferdigheter endres i et hystereseforløp, verken etter inntak av lave eller høye (rusgivende) doser. Det som foreligger av eksperimentelle studier kan tyde på at lave doser amfetamin og metamfetamin har indifferente eller prestasjonsfremmende effekter på flere typer ferdigheter (våkenhet, oppmerksomhet, reaksjonstid) hos individer som henholdsvis er i balanse eller har et underskudd på søvn. Det finnes ikke studier som avkrefter eller bekrefter at høyere doser vil gi ytterligere prestasjonsøkning, slik man ville forvente det hvis vanlige dose-effektsammenhenger gjelder. På den annen side finnes det betydelig empirisk kunnskapsgrunnlag fra andre selekterte populasjoner som tyder på at det skjer en prestasjonsforringelse $(2-4,9,10)$.

Teoretiske betraktninger trekker i retning av at økende amfetamindoser og -konsentrasjoner påvirker prestasjonsevnen på en bifasisk måte, slik at lave doser kan gi prestasjonsforbedringer (noe det finnes noen, men ikke entydige, eksperimentelle holdepunkter for), mens høyere doser gir en prestasjonsforringelse. Hysteresefenomener kan resultere $\mathrm{i}$ at amfetamineksponerte trafikanter kanskje er tryggere tidlig i forløpet enn senere, når reduserte nivåer monoamintransmittere $\mathrm{i}$ sentralnervesystemet og resulterende utmattelse dominerer det kliniske bildet. Noen aspekter ved dette er tidligere diskutert i fagtidsskrifter $(33,34)$, men har ellers ikke vært gjenstand for særlig oppmerksomhet.

Den politifaglige, påtalemessige og rettslige håndteringen ved bilkjøring etter inntak av amfetaminer bygger på blodkonsentrasjonsmålinger og utfallet av kliniske under- søkelser foretatt ved fremstilling av mistenkte for politilege. Det forutsettes - mer eller mindre implisitt - både at klassiske konsentrasjon-effekt-relasjoner eksisterer og at de gjennomførte undersøkelsene er i stand til å fange opp trafikkrelevant påvirkning. Slik er det trolig ikke når det gjelder amfetamin og metamfetamin (21) (fig 1).

\section{Konklusjon}

Medisinsk bruk av amfetamin er begrenset til lave doser, som ikke gir plasmakonsentrasjoner over $1 \mu \mathrm{mol} / 1$. Slike lave konsentrasjoner er i noen eksperimentelle studier - og spesielt hos søvndepriverte - assosiert med prestasjonsforbedringer. Ved illegal, rekreasjonell bruk av amfetamin eller metamfetamin anvendes større doser, og disse kan resultere i både eksitasjonstilstander og perioder med sløvhet og utmattelse. Dette kan bidra til redusert trafikksikkerhet og økt ulykkesfare. Dette er imidlertid ikke verifisert i eksperimentelle modeller, og det er tvilsomt om slike data kan fremskaffes; humanstudier med høye amfetamindoser byr blant annet på forskningsetiske betenkeligheter.

I den strafferettslige håndteringen av trafikksaker med amfetaminpåvirkning, legges klassiske konsentrasjon/effekt-relasjoner til grunn når skyld og straffeutmåling avgjøres. En praksis hvor påvisning av amfetaminnivåer over en viss minsteverdi knyttes direkte opp mot straffeansvar, slik det blant annet praktiseres i alkoholsaker, framstår for oss som mer rasjonell, og vil være i samsvar med råd fra en arbeidsgruppe som har utredet spørsmålet for Samferdselsdepartementet (35).

Tabell 1 Kontrollerte studier som har undersøkt om bruk av dekstroamfetamin påvirker ulike typer kjørerelaterte egenskaper. Hvis ikke annet er nevnt, er studiene placebokontrollerte, dobbeltblinde overkrysningsstudier

\begin{tabular}{|c|c|c|c|c|c|}
\hline Antall & Ruserfaring & Dose & Effekt av amfetamin & Bivirkninger & Referanse \\
\hline 29 menn $^{1}$ & Rusnaive & $10 \mathrm{mg}$ & $\emptyset k t$ risikoatferd & $\begin{array}{l}\text { Ingen av betydning } \\
\text { rapportert }\end{array}$ & 11 \\
\hline $\begin{array}{l}6 \text { kvinner } \\
\text { og } 6 \text { menn }\end{array}$ & Rusnaive & $\begin{array}{l}5 \mathrm{mg} \\
\text { eller } 10 \mathrm{mg}\end{array}$ & $\begin{array}{l}\text { Bedre resultater i hørselstest og redusert reaksjonstid } \\
\text { etter begge doser. Etter } 10 \mathrm{mg} ø \mathrm{gt} \text { interesse, årvåkenhet } \\
\text { og oppmerksomhet ved en visuell oppgave }\end{array}$ & $\begin{array}{l}\text { Forhøyet puls og systolisk } \\
\text { blodtrykk }\end{array}$ & 12 \\
\hline 14 menn & Rusbrukere & $\begin{array}{l}15 \mathrm{mg} \\
\text { eller } 30 \mathrm{mg}\end{array}$ & $\begin{array}{l}\text { Etter } 15 \mathrm{mg} \text { ingen forskjell fra placebo. Etter } 30 \mathrm{mg} \text { bedre } \\
\text { hukommelse, følelse av velvære, økt våkenhet m.m. }\end{array}$ & Tremor, muskelsvakhet & 13 \\
\hline 31 menn & Rusnaive & $\begin{array}{l}0,25 \mathrm{mg} / \mathrm{kg} \\
\text { eller } 0,50 \mathrm{mg} / \mathrm{kg}\end{array}$ & $\begin{array}{l}\text { Redusert motorisk aktivitet. Bedre resultater i oppmerk- } \\
\text { somhets- og læringsoppgaver etter begge doser }\end{array}$ & Tretthet & 14 \\
\hline $\begin{array}{l}3 \text { kvinner } \\
\text { og } 9 \text { menn }\end{array}$ & Rusnaive & $1-7,5 \mathrm{mg}$ & $\begin{array}{l}\text { Signifikant forbedring i hørselstester etter alle doser. } \\
\text { Subjektiv effekt kun etter } 7,5 \mathrm{mg} \text {. Ingen forbedring } \\
\text { i finmotorikk }\end{array}$ & $\begin{array}{l}\text { Forhøyet puls og systolisk } \\
\text { blodtrykk }\end{array}$ & 15 \\
\hline 6 menn $^{1}$ & Rusbrukere & $0,15 \mathrm{mg} / \mathrm{kg} \times 2$ & Bedre resultater i oppmerksomhetsoppgaver & Angst & 16 \\
\hline 8 menn & Rusbrukere & $\begin{array}{l}10 \mathrm{mg} \\
\text { eller } 30 \mathrm{mg}\end{array}$ & $\begin{array}{l}\text { Ingen effekt på utføringen av kognitive, motoriske } \\
\text { og perseptive oppgaver }\end{array}$ & $\begin{array}{l}\text { Ingen av betydning } \\
\text { rapportert }\end{array}$ & 17 \\
\hline 25 menn & Rusnaive & $25 \mathrm{mg}$ & Redusert reaksjonstid i en oppmerksomhetstest & $\begin{array}{l}\text { Angst, økt blodtrykk, } \\
\text { tankemyldring }\end{array}$ & 18 \\
\hline $\begin{array}{l}10 \text { kvinner } \\
\text { og } 10 \text { menn }\end{array}$ & Rusbrukere & $0,42 \mathrm{mg} / \mathrm{kg}$ & $\begin{array}{l}\text { Reduserte kjøreferdigheter, inklusive forlenget reaksjons- } \\
\text { tid på dagtid. Ingen forskjell i simulert nattkjøring }\end{array}$ & $\begin{array}{l}\text { Vanskeligheter med å sovne } \\
\text { på kvelden etter forsøket }\end{array}$ & 19 \\
\hline $\begin{array}{l}10 \text { kvinner } \\
\text { og } 10 \text { menn }\end{array}$ & Rusbrukere & $0,42 \mathrm{mg} / \mathrm{kg}$ & $\begin{array}{l}\text { Bedre resultater i oppgaver relatert til oppmerksomhet, } \\
\text { psykomotorisk funksjon og persepsjonshastighet }\end{array}$ & $\begin{array}{l}\text { Ingen av betydning } \\
\text { rapportert }\end{array}$ & 20 \\
\hline
\end{tabular}


Oppgitte interessekonflikter: Lars Slørdal er medlem av Toksikologisk gruppe, Den rettsmedisinske kommisjon. De øvrige forfatterne har ingen oppgitte interessekonflikter.

\section{Litteratur}

1. Folkehelseinstituttet. Rusmiddelstatistikk for 2006. www.fhi.no/eway/default.aspx?pid=233\&trg= MainLeft_5565\&MainArea_5661=5565:0:15,3197:1: $0: 0::: 0: 0 \&$ MainLeft_5565=5544:64013::1:5569:1:::0: 0 (21.12.2007)

2. Smart RG, Schmidt W, Bateman K. Psychoactive drugs and traffic accidents. J Safety Res 1969; 1 : 67-73.

3. Drummer $\mathrm{OH}$, Gerostamoulos J, Batziris $\mathrm{H}$ et al. The involvement of drugs in drivers of motor vehicles killed in Australian road traffic crashes. Accid Anal Prev 2004; 36: 239-48

4. Movig KLL, Mathijssen MPM, Nagel PHA et al. Psychoactive substance use and the risk of motor vehicle accidents. Accid Anal Prev 2004: 36: 631-6.

5. Caldwell JA, Caldwell JL. Fatigue in military aviation: an overview of U.S. military-approved pharmacological countermeasures. Aviat Space Environ Med 2005; 76: 39-51.

6. Kenagy DN, Bird CT. Webber CM et al. Dextroamphetamine use during B-2 combat missions. Aviat Space Environ Med 2004; 75: 381 -6.

7. Brunton LL, red. Goodman \& Gilman's The pharmacological basis of therapeutics. 11. utg. New York, NY. McGraw Hill, 2006.

8. Ellinwood EH, Nikaido AM. Simulant induced impairment: a perspective across dose and duration of use. Alcohol Drugs Driving 1987; 3: 19-24.

9. Gustavsen I, Mørland J, Bramness JG. Impairment related to blood amphetamine and/or meth amphetamine concentrations in suspected drugged drivers. Accid Anal Prev 2006; 38: 490-5.

10. Jones AW. Age- and gender-related differences in blood amphetamine concentrations in apprehended drivers: lack of association with clinical evidence of impairment. Addiction 2007; 102: 1085-91.

11. Hurst PM. The effects of $d$-amphetamine on risk taking. Psychopharmacologia 1962: 3: 283-90.

12. Hamilton MJ, Smith PR, Peck AW. Effects of bupropion, nomifensine and dexamphetamine on performance, subjective feelings, autonomic vari- ables and electroencephalogram in healthy volunteers. Br J Clin Pharmacol 1983; 15: 367-74.

13. Miller L, Griffith J. A comparison of bupropion, dextroamphetamine, and placebo in mixed-substance abusers. Psychopharmacology 1983; 80: 199-205

14. Rapoport JL, Buchsbaum MS, Weingartner $\mathrm{H}$ et al. Dextroamphetamine. Its cognitive and behavioral effects in normal and hyperactive boys and normal men. Arch Gen Psychiatry 1980; 37: 933-43.

15. Bye C, Munroe-Faure AD, Peck AW et al. A comparison of 1 - benzylpiperazine and dextroamphetamine on human performance tests. Eur J Clin Pharmacol 1973: 6: 163-9.

16. Kelly TH, Foltin RW, Fischman MW. The effects of repeated amphetamine exposure on multiple measures of human behaviour. Pharmacol Biochem Behav 1990; 38: 417-26.

17. Pickworth WB, Rohrer MS, Fant RV. Effects of abused drugs on psychomotor performance. Exp Clin Psychopharmacol 1997; 5: 235-41.

18. Asghar SJ, Tanay VAM, Baker GB et al. Relationship of plasma amphetamine levels to physiological, subjective, cognitive and biochemical measures in healthy volunteers. Hum Psychopharmacol 2003; 18: 291-9

19. Silber BY, Papafotiou K, Croft RJ et al. The effects of dexamphetamine on simulated driving performance. Psychopharmacology 2005; 179: 536-43

20. Silber BY, Croft RJ, Papafotiou K et al. The acute effects of d-amphetamine and methamphetamine on attention and psychomotor performance. Psychopharmacology 2006; 187: 154-69.

21. Silber BY, Papafotiou K, Croft RJ et al. An evaluation of the sensitivity of the strandardised field sobriety tests to detect the presence of amphetamine. Psychopharmacology 2005; 182: 153-9.

22. Somerville $W$. The effect of Benzedrine on mental or physical fatigue in soldiers. CMAJ 1946; 55 $470-6$

23. Newhouse PA, Penetar DM, Fertig JB et al. Stimulant drug effects on performance and behaviour after prolonged sleep deprivation. Mil Psychol 1992; 4: 207-33

24. Pigeau RA, Naitoh P, Buduet A et al Modafinil, $\mathrm{d}$-amphetamine, and placebo during 64 hours of sustained mantal work. Effects on mood, fatigue, cognitive performace and body temperature. Sleep Res 1995: 4: 212-28.
25. Baransky JV. Pigeau RA. Self-monotoring cognitive performace during sleep deprivation: effects of modafinil, d-amphetamine and placebo. J Sleep Res 1997: 6: 84-91.

26. Shappell SA, Neri DF, DeJohn CA. Simulated sustained flight operations and performance, part 2: Effects of dextro-methamphetamine. Mil Psycho 1992; 4: 267-87.

27. Caldwell JA, Caldwell JL, Crowley JS et al. Sustaining helicopter pilot performance with Dexedrine during periods of sleep deprivation. Aviat Space Environ Med 1995; 66: $930-7$

28. Caldwell JA, Caldwell JL, Crowley JS. Sustaining female helicopter pilot performance with Dexedrine during sustained operations. Int J Aviat Psychol 1997; 7: 15-36.

29. Caldwell JA, Smythe NK, LeDuc PA et al. Efficacy of Dexedrine for maintaining aviator performance during 64 hours of sustained wakefulness: a simulator study. Aviat Space Environ Med 2000; 71: 7-18.

30. Caldwell JA, Caldwell JL. An in-flight investigation of the efficacy of dextroamphetamine for sustaining helicopter pilot performance. Aviat Space Environ Med 1997: 68: 1073-80.

31. Wesensten NJ, Killgore WDS, Balkin TJ. Performance and alertness effects of caffeine, dextroamphetamine, and modafinil during sleep deprivation. J Sleep Res 2005: 14: 255-66.

32. Vollenweider FX, Maguire RP, Leenders $\mathrm{KL}$ et al. Effects of high amphetamine dose on mood and cerebral glucose metabolism in normal volunteers using positron emission tomography (PET). Psychiatry Res 1998; 83: 149-62.

33. Olaisen B. Rettstoksikologi på villspor. Lov og rett 2003; 42: 395-406.

34. Aune H, Bjørneboe A, Hilberg T et al. Påvirket bilkjøring - grunn til bekymring? Lov og rett 2004; 43 99-111.

35. Rapport fra arbeidsgruppe. Forslag til tiltak mot kjøring av motorvogn under påvirkning av andre rusmidler enn alkohol. Oslo: Samferdselsdepartementet, 2005. www.regjeringen.no/nb/dep/sd/dok/ hoeringer/hoeringsdok/2005/Forslag-til-tiltakmot-kjoring-under-pavirkning-av-andre-stofferenn-alkohol/3.html?id=97924 (4.11.2008).

Manuskriptet ble mottatt 28.3. 2008 og godkjent 4.11. 2008. Medisinsk redaktør Trine B. Haugen. 